\title{
Antioxidant Effect of Mulberry Leaves and Yacon Tuber Extracts in High-fat Diet-fed Rats
}

\author{
Kwangjin Kim ${ }^{1, \$, *}$, Yong Lim ${ }^{2, \$, *}$, Ji Hye Oh, ${ }^{3, *}$ Un Kyu Park ${ }^{3, *}$, Man Kyu Huh, ${ }^{4, * *}$ \\ and Seock-Yeon Hwang ${ }^{3, \dagger, * *}$ \\ ${ }^{I}$ Toxicological Evaluation and Research Department, National Institute of Food and \\ Drug Safety Evaluation, Ministry of Food and Drug Safety, Chungju 28159, Korea \\ ${ }^{2}$ Department of Clinical Laboratory Science, Dong-eui University, Busan 47340, Korea \\ ${ }^{3}$ Department of Biomedical Laboratory Science, Daejeon University, Daejeon 34520, Korea \\ ${ }^{4}$ Food Engineering and Technology Major, Dong-eui University, Busan 47340, Korea
}

The effect of mulberry leaves and yacon tuber extracts (MYE) on antioxidant was tested in this study. The present study investigated the in vivo effects of the anti-oxidative effect of MYE on catalase (CAT), superoxide dismutase (SOD), glutathione S-transferase (GST), glutathione peroxidase (GSH-Px), and thiobarbituric acid reactive substances (TBARS). The seven-day acclimation of the mice was divided into six groups: Normal diet group (NOR), high fat diet group (HFD), high fat diet with $0.5 \%$ hydroxycitric acid group diet group for positive group (HHCA), high fat diet with $1 \%$ mulberry leaf and 1\% yacon diet group (MYE-1), high fat diet with 3\% mulberry leaf and 3\% yacon group (MYE-3) and high fat diet with 5\% mulberry leaf and 5\% yacon group (MYE-5). The effect of serum antioxidant in the catalase of MYE-1, MYE-3, and HHCA comparing to HFD by $31.0 \%, 27.7 \%$ and $45.2 \%$, respectively $(P<0.05 \sim 0.01)$. The effect on hepatic antioxidant in the catalase of HFD was significantly increased $3.7(77.3 \%)$ times than that of NOR $(P<0.01)$. But, the activities of catalase were decreased significantly in MYE-1, MYE-3, MYE-5 and HHCA by 21.7\%, 24.2\%, 24.9\%, and $28.8 \%$ compared to HFD, respectively. GSH-Px was significantly decreased in MYE-1, MYE-3, MYE-5 and HHCA by $15.5 \%, 37.1 \%, 23.4 \%$, and $23.7 \%$ compared to HFD, respectively $(P<0.05)$. The activities of CAT, SOD, GST, GSH-Px, and TBARS were more significantly decreased in MYE-1 and MYE-3 than those of HFD and HHCA. MYE have shown significant effects on anti-oxidative function against high fat diet.

Key Words: Antioxidant, Catalase (CAT), Glutathione S-transferase (GST), Mulberry leaves, Yacon tuber

\section{INTRODUCTION}

Most of the potentially harmful effects of oxygen are due to the formation and activity of a number of chemical compounds, known as ROS, which have a tendency to donate oxygen to other substances (Lobo et al., 2010). The most important oxygen-containing free radicals in many disease states are hydroxyl radical, superoxide anion radical, hydrogen peroxide, oxygen singlet, hypochlorite, nitric oxide

Received: June 22, 2020 / Revised: September 14, 2020 / Accepted: September 14, 2020

*Graduate student, ${ }^{* *}$ Professor.

${ }^{\S}$ These authors contributed equally to this study.

${ }^{\dagger}$ Corresponding author: Seock Yeon Hwang. Department of Biomedical Laboratory Science, Daejeon University, 62 Daehak-ro, Dong-gu, Daejeon 34520, Korea.

Tel: +82-42-280-2802, Fax:+82-42-280-2904, e-mail: syhwang@dju.kr

(C)The Korean Society for Biomedical Laboratory Sciences. All rights reserved.

(9)This is an Open Access article distributed under the terms of the Creative Commons Attribution Non-Commercial License (http://creativecommons.org/licenses/by-nc/3.0/) which permits unrestricted non-commercial use, distribution, and reproduction in any medium, provided the original work is properly cited. 
radical, and peroxynitrite radical. There is great number of methods for determination of antioxidant capacity of foods and beverages based on different principles. A free radical can be defined as any molecular species capable of independent existence that contains an unpaired electron in an atomic orbital. The recent growth in the knowledge of free radicals and reactive oxygen species (ROS) in biology is producing a medical revolution that promises a new age of health and disease management (Aruoma, 2003).

All organisms have enzymatic and non-enzymatic mechanisms to scavenge oxidants, or to repair damage caused by ROS (Carbone et al., 2003). Among the enzymatic defenses, the removal of damaging oxygen products is catalyzed by catalase (EC 1.11.1.6), superoxide dismutase (SOD; EC 1.15.1.1), glutathione-S-transferase (GST; EC 2.5.1.18), and may protect the organisms from adverse effects of ROS (Ahmad et al., 2000; Huang et al., 2007). SOD removes the superoxide anion in a dismutation reaction, producing hydrogen peroxide and molecular oxygen. The removal of hydrogen peroxide is catalyzed by either CAT or glutathione peroxidase (GSH-Px). The activity of $\mathrm{H}_{2} \mathrm{O}_{2}$ producing cells and pathways leading to thiobarbituric acid reactive substances (TBARS) formation may change in response to many endogenic and exogenic physicochemical factors (Nowak et al., 2001). Moreover, generation/exhalation of these compounds depends on antioxidant defense in the airways. This may explain why some healthy subjects and patients with lung inflammatory disorders did not exhale detectable amounts of $\mathrm{H}_{2} \mathrm{O}_{2}$ and thiobarbituric acid reactive substances (TBARS) (Antczak et al., 1997). Most studies on $\mathrm{H}_{2} \mathrm{O}_{2}$ and TBARS exhalation in patients with lung inflammatory disorders involved only single determination of these compounds (Dohlman et al., 1993).

The mulberry (Morus alba) belongs to the genus Morus (family Moraceae). It has been cultivated in many Asian countries such as Korea, China, Japan and Thailand as folk medicine.

Yacon is known as Polymnia sonchifolia Poepping and Endlicher. It is Dicotyledoneae belonging to family Compositae and perennial tuberous root plants. The yacon is native to the Andes of South America (Novel, 1984). The tuberous root of yacon contains a large amount of fructo- oligosaccharide. It has been known that yacon does not to be absorbed into the body, prevent and relieve constipation, prevent diabetes by reducing blood lipid and blood sugar and benefit for patient dietary (Chen et al., 2000). In addition to that, yacon contains large amounts of fructose, glucose, sucrose, inulin, and fructo-oligosaccharide etc. Yacon consists of approximately $7.8 \%$ of inulin, $442 \mathrm{mg} / \mathrm{g}$ of fructooligosaccharide. The fructose and fructo-oligosaccharide in tuberous root is used as important functional component of natural sweetener. Polyphenol compound in tuberous root of yacon is major antioxidant material (Chuda et al., 1998). The phytochemical profile of leaf methanol extracts of Smallanthus sonchifolius (yacon) and their antioxidant, anticholinesterase and antidiabetic activities that could lead to the finding of more effective agents for the treatment and management of Alzheimer's disease and diabetes (Russo et al., 2015). Heat processing may affect the active constituent contents in yacon leaves, potentiating its antioxidant capacity (Ueda et al., 2019).

The effect of mulberry leaves and yacon tuber extracts (MYE) on antioxidant was tested in this study. Mulberry leaf and yacon extracts were mixed to induce a certain degree of synergistic effect. Evaluation of various major indicators to determine the effect on antioxidant in preliminary test results showed that mulberry leaf and yacon definitely gave a positive effect on those two diseases model. Thus, we carried out this study for the indicators in the experiment of the antioxidant using extracts of mulberry leaf and yacon based on the results from the preliminary study.

\section{MATERIALS AND METHODS}

\section{Preparation of mulberry and yacon extracts (MYE)}

Domestic mulberry leaves, dried that were purchased from Daegu Yangnyeong market. Domestic dried yacon purchased in the Yaconnara (Uljin, Kyungbuk, Korea) were used as a test materials. The plant materials were ground using a Retsch GM 200 mill (Fisher Bioblock, France). First, the dried test substances (mulberry leaf $1 \mathrm{~kg}$, yacon $1 \mathrm{~kg}$ ) were added in stainless vessel then $50 \%$ ethanol was added. After installation, the samples were heated for 8 hours at $85^{\circ} \mathrm{C}$. After cooling, obtained extract was filtered then $70 \%$ 
Table 1. Composition of the experimental animals

\begin{tabular}{|c|c|c|c|c|c|}
\hline \multirow{2}{*}{ Group } & \multicolumn{3}{|c|}{ Treatment } & \multirow{2}{*}{$\begin{array}{l}\text { Animals } \\
\text { (strain) }\end{array}$} & \multirow{2}{*}{ Number } \\
\hline & HFD & $\mathrm{HCA}$ & MYE & & \\
\hline NOR & - & - & - & $\begin{array}{c}\text { Rats } \\
\text { (male, SD) }\end{array}$ & 10 \\
\hline HFD & ○ & - & - & $\begin{array}{c}\text { Rats } \\
\text { (male, SD) }\end{array}$ & 10 \\
\hline HHCA & ० & O & - & $\begin{array}{c}\text { Rats } \\
\text { (male, SD) }\end{array}$ & 10 \\
\hline MYE-1 & ○ & - & $\begin{array}{c}\circ \\
(1 \%)\end{array}$ & $\begin{array}{c}\text { Rats } \\
\text { (male, SD) }\end{array}$ & 10 \\
\hline MYE-3 & ० & - & $\begin{array}{c}\circ \\
(3 \%)\end{array}$ & $\begin{array}{c}\text { Rats } \\
\text { (male, SD) }\end{array}$ & 10 \\
\hline MYE-5 & ○ & - & $\begin{array}{c}\circ \\
(5 \%)\end{array}$ & $\begin{array}{c}\text { Rats } \\
\text { (male, SD) }\end{array}$ & 10 \\
\hline
\end{tabular}

NOR, Normal. HFD, High-fat diet (HFD). HHCA, HFD + HCA (hydroxycitric acid). MYE-1, HFD + 1\% MYE (mulberry leaf + yacon). MYE-3, HFD + 3\% MYE. MYE-5, HFD + 5\% MYE

ethanol was added to the remnant to extract the second extract. The process was repeated to get the third extract. The ultrasound extraction was carried out using an ultrasonic bath (5510, Branson, USA). After extracting with ethanol, freeze-dried mulberry leaf powder and yacon were mixed with a ratio of $70 \%$ and $30 \%$ for MYE, respectively. The first and second extracts were mixed and concentrated by using vacuum evaporator $\left(50^{\circ} \mathrm{C}\right.$ or less) to make the final volume of approximately 3 liters. The each $1 \mathrm{~L}$ of extracted solution was frozen and dried in a tray with $1 \mathrm{~cm}$ thick in freeze dryer (Ilsin, Korea) to obtain the final powder. So, the rate was $13 \%$ according to $130 \mathrm{~g}$ of freezer-dried powder from $1 \mathrm{~kg}$ of mulberry leaf. In addition, the rate of yacon was $9 \%$ in accordance with $90 \mathrm{~g}$.

\section{Experimental animals and diets}

Four-weeks old male Sprague-Dawley (SD) strain rats weighing approximately 100 150 g were purchased from The DBL Ltd. (Um-sung, Chung-buk, Korea). It were acclimated to environmental for 7 days and then only healthy animals were used in the experiment. Animals were monitored in air-conditioned room at $23 \pm 2{ }^{\circ} \mathrm{C}$, relative humidity $(50 \pm 5 \%)$ and 12-hour light/dark cycle. each rat was fed at separate steel cage. Rats were provided ad libitum with distilled water.
Rats were divided into 6 groups (10 rats for each group) as following. Normal diet group (NOR), high fat diet group (HFD), high fat diet with $0.5 \%$ hydroxycitric acid (HCA, Sigma-Aldrich, St. Louis, USA). Diet group for positive group (HHCA), high fat diet with 1\% mulberry leaf and 1\% yacon diet group (MYE-1), high fat diet with 3\% mulberry leaf and 3\% yacon group (MYE-3) and high fat diet with 5\% mulberry leaf and 5\% yacon group (MYE-5) (Table 1). Rats were induced to obesity with high fat diet during 4 weeks until their body weight were more than $30 \%$ of normal range and then divided to each group and fed test substance for 4 weeks.

The diet of normal and high-fat diet group were provided with the composition of Table 2. The experimental diets contain either a normal ( $4.25 \mathrm{kcal} / \mathrm{g}$ of gross energy content) or high-fat ( $5.20 \mathrm{kcal} / \mathrm{g}$ of gross energy content) and test groups of high-fat diet with $0.5 \% \mathrm{HCA}$ in the positive control substance and concentration of 1,3, and 5\% MYE.

\section{Measurement of body weight, food and water con- sumption}

Body weights were measured at just once before treatment. Twice a week for 2 weeks after starting treatment. On the day of autopsy, body weights were measured. Meanwhile, Food and water consumption were measured twice a week for 2 weeks depends on cage and daily average food consumption (g/animal/day) daily average water consumption (mL/animal/day) were also calculated.

\section{Measurement of antioxidant enzyme activity}

The catalase activity was measured according to the Aebi method as follow (Aebi, 1974). Catalase activity was assessed by incubating the enzyme sample in $1.0 \mathrm{~mL}$ substrate $(20 \mu \mathrm{M} / \mathrm{mL}$ hydrogen peroxide in $50 \mathrm{mM} / \mathrm{L}$ sodiumpotassium phosphate buffer, $\mathrm{pH} 7.0$ ) at $37^{\circ} \mathrm{C}$ for three minutes and standardized daily using a molar extinction coefficient of $43.6 \mathrm{M}-1 \mathrm{~cm}-1$ at $240 \mathrm{~nm}$ (Lei et al., 1998). The reaction was stopped with ammonium molybdate. Absorbance of the yellow complex of molybdate and hydrogen peroxide is measured at $240 \mathrm{~nm}$ against the blank.

The measure of SOD activity is calculated from the percentage of inhibition of the reaction of xantine oxidation by 
Table 2. Dietary ingredient composition (\% by weight) of the experimental rats

\begin{tabular}{lcccccc}
\hline \hline \multicolumn{1}{c}{ Ingredient } & NOR & HFD & HHCA & MYE-1 & MYE-3 & MYE-5 \\
\hline Casein & 22.0 & 22.0 & 22.0 & 22.0 & 22.0 & 22.0 \\
Corn starch & 50.0 & 30.0 & 30.0 & 30.0 & 30.0 & 30.0 \\
Sucrose & 10.0 & 10.0 & 10.0 & 10.0 & 10.0 & 10.0 \\
Soybean oil & 10.0 & 10.0 & 10.0 & 10.0 & 10.0 & 10.0 \\
Lard & - & 20.0 & 20.0 & 20.0 & 20.0 & 20.0 \\
Cellulose & 3.0 & 3.0 & 3.0 & 3.0 & 3.0 & 3.0 \\
DL-methionine & 0.3 & 0.3 & 0.3 & 0.3 & 0.3 & 0.3 \\
Mineral mix & 3.0 & 3.0 & 3.0 & 3.0 & 3.0 & 3.0 \\
Vitamin mix & 1.0 & 1.0 & 1.0 & 1.0 & 1.0 & 1.0 \\
Choline bitartrate & 2.5 & 2.5 & 2.5 & 2.5 & 2.5 & 2.5 \\
Gross energy content $(\mathrm{kcal} / \mathrm{g})$ & 4.25 & 5.20 & 5.20 & 5.20 & 5.20 & 5.20 \\
\hline
\end{tabular}

HFD, high-fat diet. HCA, hydroxycitric acid. MYE, mulberry leaf + yacon

a) AIN mineral mixture and b) AIN vitamin mixture: Reeves et al. (1993)

xantine oxidase (optimized reaction ratio $\Delta \mathrm{A} / \min \approx 0.025$ ), which creates a superoxide anion as a substrate for SOD. The superoxide anion not used by the enzyme SOD oxidizes the cytochrome. For determination of SOD activity, $25 \mu \mathrm{L}$ of undiluted sample were mixed with $1.45 \mathrm{~mL}$ of the reaction mix (cytochrome C, $0.05 \mathrm{mM}$; xantine, $1 \mathrm{mM}$ mixed to a 10:1 ratio with addition of 5-5"-Dithio-bis (2-nitrobenzoic acid). To this mixture, $20 \mu \mathrm{L}$ xantine oxidase was added to start a reaction. The reaction was measured over $3 \mathrm{~min}$ at $550 \mathrm{~nm}$. The absorbance and percentage of inhibition were compared to the calibration curve created with different dilutions of SOD. Enzyme values are presented as U/mL.

The glutathione-S-transferase (GST) activity were measured according to Habig method (Habig et al., 1974). Briefly, GST activity was assayed spectrophotometrically by monitoring the conjugation of 1-chloro-2,4-dinitro benzene with glutathione $(\mathrm{GSH})$ at $\lambda \max =340 \mathrm{~nm}$ at $37^{\circ} \mathrm{C}$. The glutathione (GSH) content was measured according to the Uchiyama and Ellman methods (Ellman, 1959; Uchiyama and Mihara, 1978). The glutathione peroxidase (GPx) activity was measured according to the method of Paglia and Valentine (1967).

Thiobarbituric acid reactive substances (TBARS) in liver was measured using the method of Buege and Aust (1978). The liver was homogenized with $4 \mathrm{~mL}$ of $50 \mathrm{mM}$ Tris- $\mathrm{HCl}$ buffer (pH 7.4) then $1 \mathrm{~mL}$ of $20 \%$ homogeneity solution was used to dissolve the homogenized liver by adding $2 \mathrm{~mL}$ of thiobarbituric acid solution (15 $\mathrm{g}$ of trichloroacetic acid dissolved in $50 \mathrm{~mL}$ of distilled water with $0.375 \mathrm{~g}$ of TCA reagent, $25 \mathrm{~mL}$ of $1 \mathrm{~N} \mathrm{HCl}$, and $40 \mathrm{mg}$ of BHT solution containing $2 \mathrm{~mL}$ of ethanol. Total volume was made up to $100 \mathrm{~mL}$ by adding distilled water. The solution was mixed by vortex mixer for 30 seconds and cooled at room temperature after the reaction in water bath at $100^{\circ} \mathrm{C}$ for 15 minutes. The solution was centrifuged at 3,000 g for 10 minutes and the catalase activity of supernatant was measured at $535 \mathrm{~nm}$. Tetrathoxyl propane dissolved in methanol was used as a standard solution.

All chemicals were purchased from Sigma-Aldrich (St. Louis, MO, USA) and used without further purification except when mentioned specifically.

\section{Legislation and animal treatments}

Investigators complied with the animal ethics law. All procedures were approved by the institutional ethics committee for the care and use of animals. The number of Institutional Animal Care and Use Committee is DJUARIB201205 .

\section{Statistical analysis}

All numbers in data represent mean \pm standard deviation. Statistical significance were analyzed by Duncan's multiple range test followed by one-way analysis of variance 
(ANOVA). and accepted if $P<0.05$. Statistical analysis was performed using the Statistical Package for Social Sciences 12.0 (SPSS) program.

\section{RESULTS}

\section{Effects of MYE on antioxidant activity in serum}

Fig. 1 was serum antioxidant enzyme activities on catalase (A) and SOD (B) in high-fat diet-fed rats with MYE. Conveniently, the values were the result of conversion to $\%$ for comparison between groups. The effect on serum antioxidant in the catalase of HFD was significantly increased 3.7 $(125.2 \%)$ times than NOR $(P<0.01)$. However, significantly decreased MYE-1, MYE-3 and HHCA by 31.0\%, 27.7\% and $45.2 \%$ compared to HFD $(P<0.05 \sim 0.01)$. The SOD of HFD was significantly increased $178.6 \%$ compared to NOR $(P<0.01)$. But, there was significantly decreased MYE-3 and MYE-5 and HHCA by $22.8 \%, 24.5 \%$, and $35.9 \%$ compared to HFD, respectively $(P<0.05 \sim 0.01)$ (Fig. 1).

\section{Antioxidant effects of MYE in the liver}

The effect of hepatic antioxidant in the catalase of HFD was significantly increased $3.7(77.3 \%)$ times than that of NOR $(P<0.01)$. But, there was significantly decreased MYE1, MYE-3, MYE-5, and HHCA comparing to HFD by $21.7 \%, 24.2 \%, 24.9 \%$, and $28.8 \%$, respectively $(P<0.05 \sim$

\section{A}



B

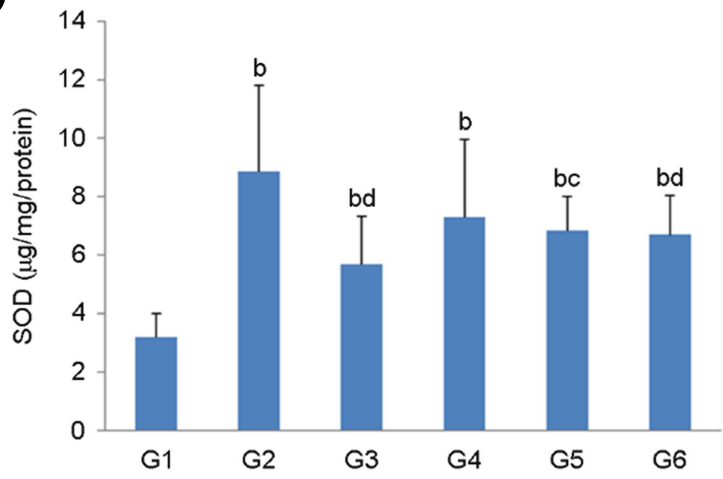

Fig. 1. Serum antioxidant enzyme activities on catalase (A) and SOD (B) in high-fat diet-fed rats with MYE (mulberry leaf + yacon).

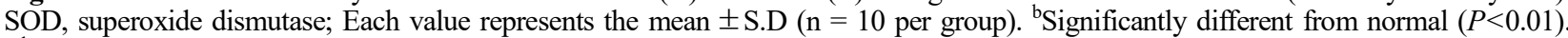
${ }^{\mathrm{c}, \mathrm{d}}$ Significantly different from HFD alone $(P<0.05, P<0.01)$.

A

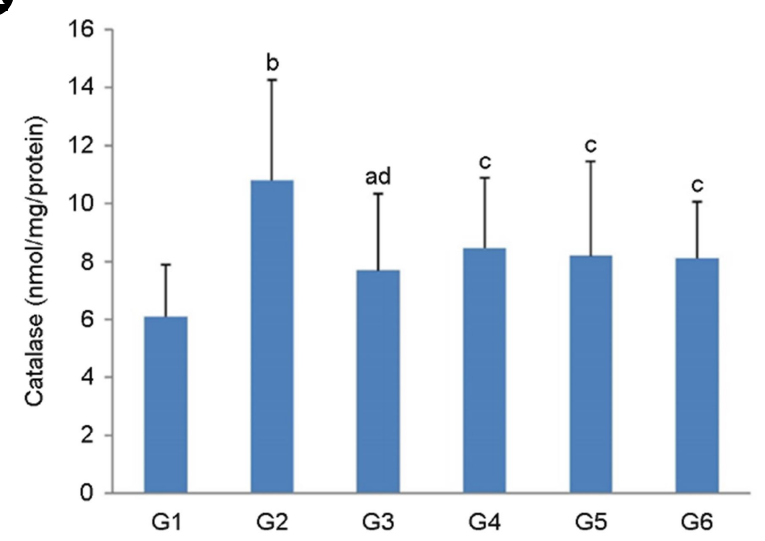

B

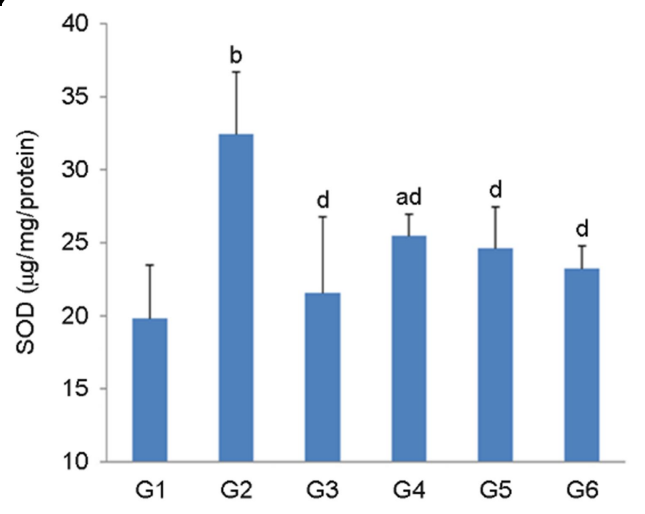

Fig. 2. Hepatic antioxidant enzyme activities on catalase (A) and SOD (B) in high-fat diet-fed rats with MYE (mulberry leaf + yacon). SOD, superoxide dismutase. ${ }^{\mathrm{a}, \mathrm{b}}$ Significantly different from normal $(P<0.05, P<0.01)$. ${ }^{\mathrm{c}, \mathrm{d}}$ Significantly different from $\mathrm{HFD}$ alone $(P<0.05$, $P<0.01)$. 
(A)

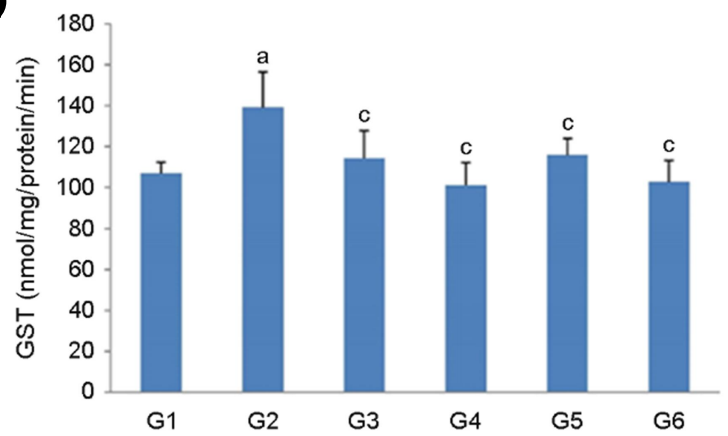

B

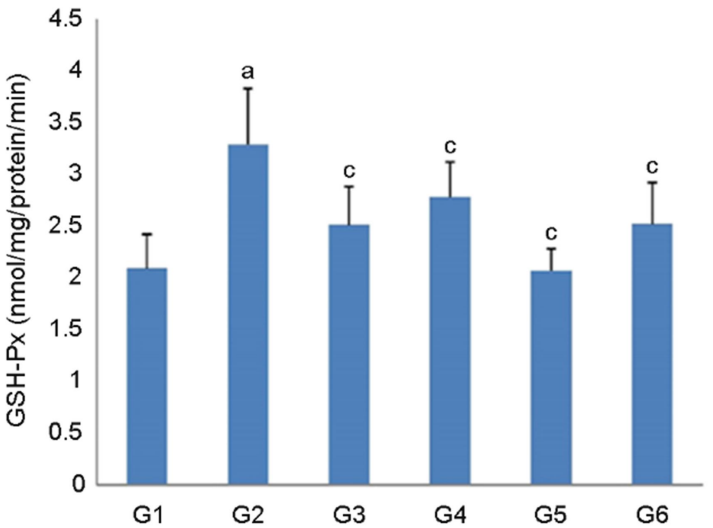

C

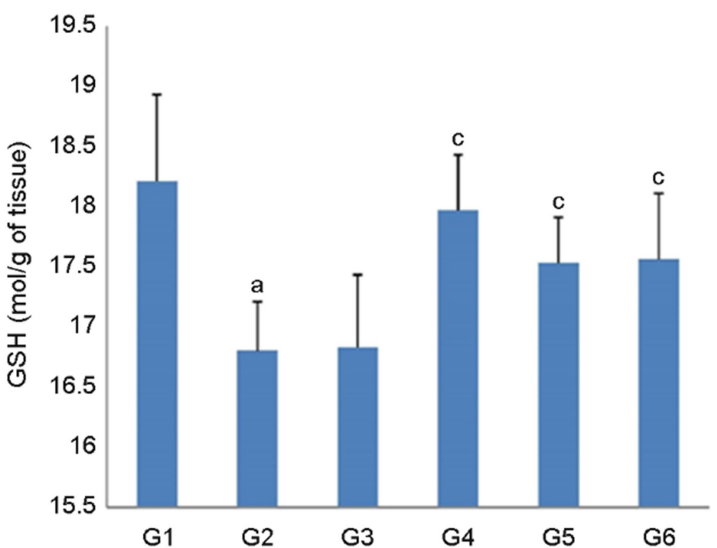

Fig. 3. Effect of MYE (mulberry leaf + yacon) on hepatic cytoslic GST (A), GPx (B) and GSH (C) activities in high-fat diet-fed rats. GST, glutathione-S-transferase; GSH-Px, glutathione peroxidase; $\mathrm{GSH}$, glutathione; ${ }^{\mathrm{c}}$ Significantly different from HFD alone $(P<$ $0.05)$.

0.01). The SOD significantly increased $63.6 \%$ in HFD compared to NOR $(P<0.01)$. However, significantly decreased MYE-1, MYE-3, MYE-5 and HHCA comparing to HFD by $21.5 \%, 24.1 \%, 28.3 \%$, and $33.6 \%$, respectively $(P<0.01)$ (Fig. 2). The GST of HFD was significantly increased 30.2\% than that of NOR $(P<0.05)$. But, significantly decreased MYE-1, MYE-3, MYE-5 and HHCA by $27.4 \%, 16.7 \%$, $26.2 \%$, and $17.9 \%$ compared to HFD $(P<0.05)$. The GSHPx of HFD was significantly increased $57.4 \%$ than that of NOR $(P<0.05)$. But, GSH-Px was significantly decreased in MYE-1, MYE-3, MYE-5 and HHCA comparing to HFD by $15.5 \%, 37.1 \%, 23.4 \%$, and $23.7 \%$, respectively $(P<0.05)$. The GSH of HFD was significantly decreased compared to NOR by $77.4 \%(P<0.05)$ But, there was not shown significant difference in HHCA compared to HFD. Whereas the values of GSH were increased significantly in MYE-1, MYE-3, MYE-5 comparing to HFD by $7.0 \%, 4.3 \%, 4.5 \%$, respectively $(P<0.05)$ (Fig. 3).

\section{DISCUSSION}

Major effective ingredients of the mulberry leaf for biological functions are known as flavonoids, amino acid, vitamins and minerals etc. Mulberry leaves contain several bioactive components such as quercetin, kaempferol, rutin, astragalin, resveratrol, $\gamma$-aminobutyric acid and 1-deoxynojirimycin. Quercetin, a member of the flavonoids family is a prominent dietary antioxidant and ubiquitously present in foods that exerts beneficial health effects. The ability of quercetin to scavenge reactive oxygen species (ROS) has been suggested to be involved in possible beneficial health effects. Mulberry leaves have been reported to be rich in flavonoids (Pierpoint, 1986). Flavonoids are of combined C6C3-C6 type with carbon skeleton structure in which 2 phenyl is mediated with $\mathrm{C} 3$ chain, and divided into 4 groups such as anthocyanin, flavone, flavonol and isoflavone according to the structure and position of substituent. The antioxidant mechanism by flavonoid is still uncertain, but the inhibitory effect of flavonoid on the formation of free radicals was widely accepted (Panche et al., 2016). In this study, the antioxidant mechanism was considered flavonoids containing rutin, quercetin and kaempferol morin (Murota and Terao, 2003; Rotell et al., 2003).

The tuberous root of yacon contains a large amount of fructo-oligosaccharide. The tuberous root of yacon has been 
known as high developmental value in health functional food industry since it contains 2 times more fructose than sucrose (Doo et al., 2000).

Superoxide produced in a normal cell is transformed to $\mathrm{H}_{2} \mathrm{O}_{2}$ by SOD and then metabolized to oxygen and water by catalase or glutathione peroxidase (GSH-Px). When superoxide is overproduced in the presence of transition metals, hydroxyl radical is produced by Fenton reaction or superoxide Har-Weiss with $\mathrm{H}_{2} \mathrm{O}_{2}$. Such hydroxyl radical reportedly hinders GSH/GSSG to maintain the normal ratio, thus accumulating GSSG. This inactivate the combining of hydroxyl radical with -SH from GSH. With enzyme reaction, SOD is known to remove superoxide radical which is produced by respiration within cells, thus preventing hydrogen peroxide from accumulating and increasing anti-oxidative function (Che et al., 2016). In this study, such effect of SOD was observed in MYE group. It is assumed that SOD expressed anti-oxidative effects to reduce oxidative stress of cells produced by high fat diet to control liver damage, thus increasing the activation of SOD. Catalase is one of oxidoreductases which break down $\mathrm{H}_{2} \mathrm{O}_{2}$, a substance which oxidizes fat and organic compound, into $\mathrm{O}_{2}$ or $\mathrm{H}_{2} \mathrm{O}$ and excrete them. That the liver contains a significant amount of catalase is to break down $\mathrm{H}_{2} \mathrm{O}_{2}$ produced by oxidation of fat and organic compounds and breakdown of fat (Lobo et al., 2010). In this study, high-fat diet-fed group also showed such results. In MYE treated group, on the other hand, a significant increase was also observed compared with high fat diet group, assuming that antioxidants of the test substance removed free radical.

The content of glutathione (GSH) significantly decreased $(P<0.05)$ in a high-fat diet-fed group compared with a control group, whereas glutathione was significantly increased in MYE groups compared to that of high-fat diet-fed group $(P<0.05)$. In general GSH in cells play a role of biophylaxis against oxidation and metabolic stress in exogenous and endogenous substrates, regenerating anti-oxidative enzymes (Hasanuzzaman et al., 2017). Also, glutathione participates directly in the neutralization of free radicals and reactive oxygen compounds and is used in metabolic and biochemical reactions such as DNA synthesis and repair, protein synthesis, prostaglandin synthesis, amino acid transport, and enzyme activation (Kurutas, 2016). This result caused liver damage and inflammation in obesity by inhibiting the protective effect of antioxidant and liver damage appeared (Yang et al., 2018). GST showed a significant increase in a high-fat diet-fed group compared with a control group, whereas significantly decreased in all MYE group including positive control group (HCA) compared with high-fat diet-fed group $(P<0.05)$. It is reported that GST captures thiol of glutathione into electrophilic toxic substances produced in the body and depletes such toxic substances (Rubino, 2015). Based on this report, it is assumed that an decreasing trend observed above is resulted from the extract that captures glutathione into toxic substances and catalyzes the excretion, protecting the liver from damage and inflammation caused by obesity. GSH-Px, an enzyme which removes and converts $\mathrm{H}_{2} \mathrm{O}_{2}$, showed the same results as GST discussed above. Such results are interpreted as follows: The test substance reduced the activation of GSH-Px, thus hindering the generation of $\mathrm{H}_{2} \mathrm{O}_{2}$ because the test substance showed a significant effect in indexes related to diabetes caused by obesity with high diet fat, the results are affected by active components with antioxidative effects by the test substance (Manna and Jain, 2015).

These effect of MYE seems to result in inhibiting the oxidative reaction in liver from the high-fat diet-fed rats. Thus, it was concluded that MYE significantly improve the obesity-induced changes in high-fat diet-fed rats and has a potential for alternative food to prevent various disease caused by obesity.

Conclusion, to evaluate the antioxidant effect of mulberry leaf and yacon tuber (MYE), 1, 3, or 5\% of them were treated to Sprague-Dawley rats. Anti-oxidative effect of MYE was observed by measuring the levels of GSH, lipoperoxide, SOD, Catalase, GST and GSH-Px. In summary, it is concluded that MYE have significant effects on antioxidative function.

\section{ACKNOWLEDGEMENT}

None.

\section{CONFLICT OF INTEREST}

The authors declare that they have no conflict of interest. 


\section{REFERENCES}

Aebi H. Catalase in Methods Analysis (Vergmeyer HU. Ed). 1974. pp. 673-680. Verlag Chemie/Academic Press Inc., Weinheim, NY, USA.

Ahmad S, Kitchin KT, Cullen WR. Arsenic species that cause release of iron from ferritin and generation of activated oxygen. Arch Biochem Biophy. 2000. 382: 195-202.

Antczak A, Nowak D, Shariati B, Krol M, Kurmanowska Z. Increased hydrogen peroxide and TBA-reactive products in expired breath condensate of asthmatic patients. Eur Respir J. 1997. 10: 1235-1241.

Aruoma OI. Methodological consideration for characterization for potential antioxidant actions of bioactive components in plants foods. Mutat Res. 2003. 532: 9-20.

Buege JA, Aust SD. Microsomal lipid peroxidation. Methods Enzymol. 1978. 52: 302-310.

Carbone MC, Tatone C, Monache SD, Marci R, Caserta D, Colonna R. Antioxidant enzymatic defences in human follicular fluid: characterization and age-dependent changes. Mol Hum Reprod. 2003. 9: 639-643.

Che M, Wang R, Wang HY, Zheng XFS. Expanding roles of superoxide dismutases in cell regulation and cancer. Drug Discov Today. 2016. 21: 143-149.

Chen HL, Lu YH, Lin JJ, Ko LY. Effects of fructooligosaccharide on bowel function and indicators of nutritional status in constipated elderly men. Nutr Res. 2000. 20: 1725-1733.

Chuda Y, Suzuki M, Nagata T, Tsushida T. Contents and cooking loss of three quinic acid derivatives from garland (Chrysanthemun cornariub L.). J Agric Food Chem. 1998. 46: 1437 -1439 .

Dohlman AW, Blackm H, Royall JA. Expired breath hydrogen peroxide is a marker of acute airway inflammation in pediatric patients with asthma. Am Rev Respir Dis. 1993. 148: 955-960.

Doo HS, Li HL, Kwon TO, Ryu JH. Changes in sugar contents and storability of yacon under different storage conditions. Korean J Crop Sci. 2000. 45: 300-304.

Ellman GL. Tissue sulfhydryl groups. Arch Biochem Biophy. 1959. 82: 70-77.

Habig WH, Pabst MJ, Jakoby WB. Glutathione S-transferase. The first enzymatic step in mercapturic acid formation. J Biol Chem. 1974. 249: 7130-7139.

Hasanuzzaman M, Nahar K, Anee TI, Fujitacorresponding M.
Glutathione in plants: biosynthesis and physiological role in environmental stress tolerance. Physiol Mol Biol Plants. 2017 23: $249-268$

Huang DJ, Zhang YM, Song G, Long J, Liu JH, Ji WH. Contaminants-induced oxidative damage on the carp Cypinus cario collected from the upper Yellow River, China. Environ Monit Assee. 2007. 128: 483-488.

Kurutas EB. The importance of antioxidants which play the role in cellular response against oxidative/nitrosative stress: current state. Nutr J. 2016. 15: 71.

Lei B, Adachi N, Arai T. Measurement of the extracellular $\mathrm{H}_{2} \mathrm{O}_{2}$ in the brain by microdialysis. Brain Res Brain Res Protoc. 1998. 3: 33-36.

Lobo V, Patil A, Phatak A, Chandra N. Free radicals, antioxidants and functional foods: Impact on human health. Pharmacogn Rev. 2010. 4: 118-126.

Manna P, Jain SK. Obesity, oxidative stress, adipose tissue dysfunction, and the associated health risks: Causes and therapeutic strategies. Metab Syndr Relat Disord. 2015. 13: 423-444.

Murota K, Terao J. Antioxidative flavonoid quercetin: implication of its intestinal absorption and metabolism. Arch Biochem Biophys. 2003. 417: 12-17.

Novel V. The lost crops of the Incas. Ceres. 1984. 17: 37-40.

Nowak D, Kałucka S, Białasiewicz P, Krol M. Exhalation of $\mathrm{H}_{2} \mathrm{O}_{2}$ and thiobarbituric acid reactive substances (TBARS) by healthy subjects. Free Radic Biol Med. 2001. 30: 178-186.

Paglia DE, Valentine WN. Studies on the quantitative and qualitative characterization of erythrocytes glutathione peroxidase. J Lab Clin Med. 1967. 70: 158-169.

Panche AN, Diwan AD, Chandra SR. Flavonoids: an overview. J Nutr Sci. 2016. 5: e47.

Pierpoint WS. Flavonoids in the human diet in plant flavonoids in biology and medicine: biochemical, pharmacological, and structure-activity relationships (Cody V, Middleton E, Harborne JB. Eds.). 1986. pp. 125-140. Alan R. Liss, Inc., NY, USA.

Reeves PG, Nielsen FH, Fahey GC Jr. AIN-93 purified diets for laboratory rodents: final report of the American Institute of Nutrition ad hoc writing committee on the reformulation of the AIN-76A rodent diet. J Nutr. 1993. 123: 1939-1951.

Rotell AE, Guardia T, Jaurez AO, de la Rocha NE, Pelzer LE. Comparative study of flavonoids in experimental models of inflammation. Pharmacol Res. 2003. 48: 601-606.

Rubino FM. Toxicity of Glutathione-binding metals: A review of targets and mechanisms. Toxics. 2015. 3: 20-62.

Russo D, Andrade P, Fernadez E, Valentao P. Evaluation of 
antioxidant, antidiabetic and anticholinesterase activities of Smallanthus sonchifolius landraces and correlation with their phytochemical profiles. Int J Mol Sci. 2015. 16: 17696-17718.

Uchiyama M, Mihara M. Determination of malondialdehyde precursor in tissue by thiobarbituric acid test. Anal Biochem. 1978. 86: 271-278.

Ueda Y, Matsuda Y, Murata T, Hoshi Y, Kabata K, Ono M. Increased phenolic content and antioxidant capacity of the heated leaves of yacon (Smallanthus sonchifolius). Biosci Biotechnol Biochem. 2019. 83: 2288-2297.
Yang JP, Shin JH, Seo SH, Kim SG, Lee SH, Shin EH. Effects of antioxidants in reducing accumulation of fat in hepatocyte. Int J Mol Sci. 2018. 19: 2563.

https://doi.org/10.15616/BSL.2020.26.3.201

Cite this article as: $\mathrm{Kim} \mathrm{K}$, Lim Y, Oh JH, Park UK, Huh MK, Hwang SY. Antioxidant Effect of Mulberry Leaves and Yacon Tuber Extracts in High-fat Diet-fed Rats. Biomedical Science Letters. 2020. 26: 201-209. 